\title{
Erratum to: Second California Assessment: integrated climate change impacts assessment of natural and managed systems. Guest editorial
}

\author{
Guido Franco • Daniel R. Cayan • Susanne Moser • \\ Michael Hanemann • Myoung-Ae Jones
}

Published online: 22 June 2012

(C) Springer Science+Business Media B.V. 2012

\section{Erratum to: Climatic Change (2011) 109 (Suppl 1):S1-S19 DOI 10.1007/s10584-011-0318-z}

In the original study included in this special issue, Auffhammer and Aroonruengsawat (2011) reported a $55 \%$ increase in household electricity consumption by 2100 . The authors later discovered that the large increase was due to a coding error in the simulation and ran the models again with corrected codes. The corrected results now show that the household electricity consumption rate by 2100 one order of magnitude smaller than the original estimation. Our discussion in section 3.7 on the energy demand and hydropower generation covering their study should now read as below:

The online version of the original article can be found at http://dx.doi.org/10.1007/s10584-011-0318-z.

G. Franco $(\bowtie)$

Public Interest Energy Research, California Energy Commission, Sacramento, CA, USA

e-mail: Gfranco@Energy.state.ca.us

D. R. Cayan

Scripps Institution of Oceanography, University of California, San Diego, La Jolla, CA, USA

S. Moser

Stanford University, Santa Cruz, CA, USA

M. Hanemann

Economics Department, Arizona State University, Tempe, AZ, USA

M. Jones

Scripps Institution of Oceanography, University of California, San Diego, Sacramento, CA, USA

D. R. Cayan

U.S. Geological Survey, La Jolla, CA, USA

S. Moser

Susanne Moser Research \& Consulting, Santa Cruz, CA, USA 
Auffhammer and Aroonruengsawat (2011) expanded upon previous studies (Miller et al. 2008; Franco and Sanstad 2008) in the 2009 Assessment by evaluating climate impacts on electricity demand. They used a unique data set consisting of household level residential electricity consumption to estimate potential changes in electricity demand in the residential sector at the U.S. mail zip code level. Their estimated impacts are consistent with what has been reported in the past (Miller et al. 2008). What the new study adds is high spatial resolution showing that annual increases in electricity demand would grow at a faster rate in the Central Valley and the southeastern parts of the state. 